\title{
Multicriteria Model Based on FITradeoff Method for Prioritizing Sections of Brazilian Roads by Criticality
}

\author{
Mateus A. Martins $(\mathbb{D}){ }^{1}$ Thalles V. Garcez $\left(\mathbb{D},{ }^{1}\right.$ Ana Paula H. de Gusmão ${ }^{D},{ }^{1,2}$ \\ Lucimário G. O. Silva $\mathbb{D}^{1}{ }^{1}$ and Jônatas A. de Almeida $\mathbb{1}^{1}$ \\ ${ }^{1}$ Management Engineering, Universidade Federal de Pernambuco, Caruaru 55014-900, Brazil \\ ${ }^{2}$ Management Engineering, Universidade Federal de Sergipe, São Cristóvão 49100-000, Brazil \\ Correspondence should be addressed to Thalles V. Garcez; thalles.garcez@ufpe.br
}

Received 25 September 2020; Revised 18 November 2020; Accepted 18 December 2020; Published 29 December 2020

Academic Editor: Juan Carlos Leyva Lopez

Copyright (C) 2020 Mateus A. Martins et al. This is an open access article distributed under the Creative Commons Attribution License, which permits unrestricted use, distribution, and reproduction in any medium, provided the original work is properly cited.

\begin{abstract}
Three of the most important objectives of the Federal Road Police (Patrol) when managing the traffic on federal roads in Brazil are to ensure that there is an efficient movement of traffic under stable conditions and minimal traffic congestion problems that the federal highways are safe and that accidents do not occur. Therefore, multiple matters are relevant for road safety and user security, such as prompt maintenance of these highways, regular monitoring of their state of conservation and their characteristics; controlling the traffic; and preventing and combatting criminal activities on the highways. However, considering the vast network and different conditions of roads, the different types of traffic accidents and their consequences, and different levels of violence on federal roads, it is essential that these roads undergo regular maintenance and regular inspections, are constantly patrolled, and are subject to continuous improvements. Therefore, defining the prioritization and criticality of roads takes on the characteristics of a multicriteria decision, given the multidimensional aspects of the risks inherent in them. Thus, this paper presents a multicriteria decision model for prioritizing road sections, based on their criticality and the risks that users face. The model was applied using the FITradeoff method, due to its flexibility and due to it requiring less cognitive effort from the decision-maker with regard to providing information regarding his/her preferences. A case study was undertaken on a set of the federal roads of the state of Pernambuco (Brazil), covering 22 different sections with different characteristics. As a result, it was possible to rank and identify the most critical sections of a highway. The use of FITradeoff gave support to decision-making on ordering the sections and also let a general analysis of the data be undertaken.
\end{abstract}

\section{Introduction}

Worldwide, about 1.35 million people die every year in traffic accidents [1]. Moreover, between 20 and 50 million other people have some degree of physical or psychological sequelae. In addition to the irreparable loss of human lives, the sequelae and trauma of victims, and the immeasurable impact on the families affected and on the communities in which they live, the monetary costs of traffic accidents for society as a whole are high. The social and economic costs amount to $3 \%$ of the gross domestic product (GDP) of all countries in the world [2].

In 2016, deaths caused by traffic accidents rose by two positions in the ranking of deaths from all causes due to the increase in road accident fatalities, which, therefore, became the eighth leading cause of death. There were 1.4 million such deaths (2.5\% of all deaths), and road accidents were the leading cause of death among young people aged 15 to 29 years. In contrast, when only high-income countries are considered, traffic fatalities are not among the top ten causes of death, thus reinforcing how serious this possible cause of death is for the 15-29-year-old age group, especially in lowand middle-income countries [3].

In Brazil, tens of thousands of people die on roads and tens of millions are injured or disabled every year. In 2015, for instance, 38,651 traffic fatalities were recorded. Brazil was ranked third among the countries with most traffic deaths in absolute terms. When the ratio of the number of deaths to 
the total number of inhabitants is taken into account, Brazil ranks 14th, with an average of 19.7 deaths per 100,000 inhabitants [1].

Hence, the large number of traffic accidents makes them the leading cause of adverse impacts on humans such as death, injury, and hospitalization, resulting in high economic and social costs. In 2014, approximately 170,000 traffic accidents generated a cost of $\mathrm{R} \$ 12.3$ billion for Brazil, of which $64.7 \%$ were associated with the victims of such accidents. This included expenditure on health care and the costs arising from loss of production due to injuries or death, and $34.7 \%$ were related to vehicles, such as damage to public and private property, loss of cargo, and the cost of removing wrecked and damaged vehicles [4].

Intervening in the road system and making improvements to the roads, in order to reduce the number of deaths and injured victims and thus to reduce the damage and losses from accidents, is a major challenge for transport management and engineering. Therefore, studying the most critical locations is an appropriate way to establish a policy for improving safety levels on roads, thereby prioritizing critical roads [5]. Furthermore, considering that resources are limited, it is not possible to invest in all roads simultaneously, so the most critical roads must be targeted [6].

It is noteworthy that the issue of prioritizing road sections is not restricted only to issues related to traffic accidents, since security issues also affect users of roads. Some of the crimes that can occur within the jurisdiction of federal highways are drug trafficking, arms trafficking, human trafficking, smuggling, environmental crimes, theft of cargo and theft of vehicles, and sexual exploitation of children and adolescents. Therefore, in addition to traffic safety issues on roads, the role of the Federal Road Police (FRP) in Brazil also includes endeavoring to ensure that federal roads are not used to support criminal activities such as the transport of illegal drugs, arms, contraband, and people trafficking nor as to the stage for crimes such as the hijacking of goods and vehicles or hold-ups of long-distance buses and robbing passengers. Similarly, another duty of the FRP is to identify and arrest perpetrators of crime travelling on federal roads in public or private transport including stolen vehicles. In the first half of 2020, about 316 tons of marijuana and about 14 tons of cocaine were seized by the FRP in Brazil, corresponding to about $25 \%$ and $15 \%$ of all marijuana and cocaine, respectively, seized in Brazil [7]. As to the hijacking of trucks and the theft of cargo, these are crimes that have been shown to be constantly increasing in Brazil, and the FRP has had to devote more and more resources to combat them. In fact, Brazil is one of the countries in which the security of cargo is at the highest risk from criminal activity. The estimated direct cost of the theft of cargo to the Brazilian economy is 442 million USD per year, an amount that has been increasing in the last decade [8].

It is emphasized that some characteristics (condition/ state) of the roads can influence issues associated with crime [9]. For example, drivers can avoid driving at certain times on certain roads, for fear of being held up; certain conditions of the road may also facilitate criminal activity, such as having to reduce speed on sections of a road which is in a poor state of repair; road sections that are not regularly policed favor the circulation of narcotics, and raise issues about the control of borders. Finally, when looking to improve the "general conditions" of the road, the objective is to reduce both accidents and criminal actions and thus to improve safety in a more comprehensive way and from a wider perspective than other countries in which the extent of criminal activity on highways is considerably less in volume and value than in Brazil.

One way to reduce the problems related to the costs and severity of the consequences generated by road accidents is by studying the most critical sites to establish a policy of improving the level of safety on the roads, thus guiding what priority to give to the most critical road sections. However, it should be noted that this type of study involving the phenomenon of road safety is complex and should involve detailed aspects of the causality of accidents and injuries, not only data on the number of occurrences. Road crashes are a consequence of multiple factors, which are generally grouped in relation to the infrastructure (road condition), the vehicle, and the driver (human state of health and fitness to drive) [10-15]. Additionally, given that this study addresses issues associated with the scope of the FRP, violence on roads is considered to be another dimension that the FRP must deal with. Such violence can be regarded as a form of criminality, not only when there are acts of aggression and physical assault but also when drivers are under the influence of alcohol and/or drugs or are otherwise incapable of driving safely (e.g., truck drivers driving continuously for longer than the law permits and falling asleep at the wheel, a not uncommon occurrence). Therefore, this involves a multidimensional concept that cannot be captured by a single indicator, which implies that there is a multiobjective feature to the problem [16-18]. It can be seen, from this overview of the duties of the FRP, that traffic accidents and violence on the roads compete for common resources, for example, since the patrol that deals with traffic accident issues also deals with criminality.

Given this structure, a multicriteria approach to deal with this type of problem is frequently taken $[6,19-21]$. Within the different approaches used in multicriteria analysis, additive models stand out [22-25]. However, an inherent difficulty when using these methods concerns the elicitation of weights, given the cognitive effort required in this process $[19,20,24,26,27]$.

Thus, this paper proposes using a multicriteria approach to address the problem [21]. To this end, considering the advantages that will be discussed below, the FITradeoff (flexible and interactive tradeoff) method [24], widely used in the literature $[22-25,28]$, was used to identify the most critical road sections in the state of Pernambuco and to indicate the amount of future investments needed in order to improve road safety and security.

In view of the difficulty in the elicitation process, a procedure must be chosen, which in addition to mitigating the effort required in the process, also takes proper account of the compensation among the criteria. In this respect, the FITradeoff method [24] stands out because it offers a procedure of flexible elicitation of weights or scale constants 
based on the traditional axiomatic procedure of tradeoff elicitation, which is one of the most used when considering additive methods. However, unlike the traditional procedure, which takes into account the relationship of indifference, the FITradeoff also admits the relationship of preference which makes the cognitive effort that the decision-maker (DM) needs to make smaller, while, at the same time, the possibility of inconsistencies regarding the DM's judgments is reduced [24].

The article is structured as follows: in the related work section, a literature review on assessing the conditions of roads using a multicriteria approach is presented; in the Materials and Methods section, a framework developed for this application is presented and the FITradeoff method is explained; the subsequent section is devoted to the Case study which was used to analyze the decision problem that prompted this study. The Results and Discussion section presents some insights about the results and some conclusions are drawn in the last section.

\section{Related Work}

Given the complexity of studies related to the factors that link accidents and road conditions, a multidimensional analysis is often required. Hence, some authors use a multicriteria approach in order to analyze the multiple dimensions of the problem.

The performance indicators of traffic safety are listed in a global index and combined with linguistic descriptors that are based on the knowledge of experts by a fuzzy TOPSIS hierarchical model [16]. The model proved to be useful because it helps the general public to have a good understanding of the results, thereby supporting the desired policy. This was achieved by displaying several road safety performance indicators in a single composite index together with experts' comments.

This is also commented on by Tešić et al. [19], who used data envelopment analysis (DEA) to assess the efficiency of European countries in terms of traffic safety on the basis of the following criteria: laws about driving and alcohol, speed limits, and adequacy of protection systems (e.g., seat belts, airbags, central reservation or protective barriers, condition of vehicles, condition of roads, and provision of trauma management). The study highlighted the importance of selecting indicators that have the greatest influence on the outcome. The result depends on the collection and quality of data, on the method used and on the indicators. In addition, the study pointed out that a greater number of indicators provide a higher quality result so that DMs can precisely define actions and identifying strengths and weaknesses. In contrast, in practice, there is a need to use an index that has a limited number of indicators that provide enough quality to compare countries.

Fancello et al. [29] used a multicriteria ranking method with the objective of comparing different road sections regarding safety conditions. Therefore, an algorithm based on the ELECTRE III method was used to rank road sections in a real study case. Hence, the analysis of intervention priorities was based on the final ranking. In a similar approach, Fancello et al. [20] developed a decision support system (DSS) for road analysis incorporating different indicators. Their main objective was to determine which sections require interventions to improve safety conditions. In multicriteria terms, concordance analysis was used. With the objective of improving both previous methodologies, Fancello et al. [6] combined two multicriteria methods (VIKOR and TOPSIS) for comparison of the concordance analysis. They used eight criteria based on traffic volume and the geometrics of road sections.

Temrungsie et al. [27] used the analytic hierarchy process (AHP) method as a tool for learning and prioritizing the information that can prevent and reduce accidents. The subcriteria in the analysis of this study were framed into 4 main criteria: engineering, economic, socioenvironmental, and safety. To collect the information necessary for the method, a questionnaire was applied to 100 respondents distributed in different expert groups.

However, still using the AHP method, Kanuganti et al. [30] aimed at prioritizing safety requirements of a simple additive weighting category of rural roads in India. Three different methods were analyzed for this purpose: simple additive weighting, AHP, and fuzzy AHP.

In Khorasani et al. study [31], a multicriteria method for assessing the safety performance of 21 European countries was presented. The evaluation of the countries was based on a survey of 11 indicators and the simple additive weighting method was used. To determine the weights, the entropy method applied to the decision matrix was used.

Castro-Nuño and Arévalo-Quijada [32] presented two multidimensional safety indicators that combine a set of criteria related to the economy, demography, and sustainability in urban transport. These indicators were used to determine safety performance in 50 Spanish provinces. Thus, a multicriteria analysis using the PROMETHEE (Preference Ranking Organization Method for Enrichment Evaluation) method was applied along with the entropy method of determining weights.

With the same aim of determining an aggregation index, Rosić et al. [33] used different models with the aim of increasing efficiency in generating a composite safety index in relation to roads. Thus, the authors based the construction of their index on a combined analysis using DEA and TOPSIS to present a model for selecting composite indicators by using the PROMETHEE-RS method. Based on the same idea, Chen et al. [34] presented a methodology for formulating a composite index based on the TOPSIS-RSR entropy methodology.

For Hermans et al. [35], the idea of building a composite road safety indicator was used on the basis of a methodology that applies ordered weighted averaging (OWA) operators. Based on this approach, seven indicators were combined into a single indicator for evaluating different countries. The weights of each indicator were determined by the relative importance of each criterion by means of the AHP method.

In a broader context, Rodrigues et al. [36] presented a road network classification model based on traffic accidents integrated with a geographical information system. In the model, an equation was defined to obtain a road safety 
index based on the following indicators: severity, damage to property only, and the costs of accidents. In addition to the advantage of classification, the model enabled the analysis of the spatial coverage of accidents with a view to determining the location of regions with the highest accident rates.

In the context of expansion using a DEA model, Shen et al. [37] presented a generalized multiple layer data envelopment analysis (MLDEA) model. The model was applied to a case study that evaluated the performance of safety measures in a set of 19 European countries and used 13 hierarchical performance indicators of safety.

Furthermore, there are several cases of road accidents that have been attributed to human factors due to crimerelated activities. A high level of crime may affect road transport in many different ways. For instance, police pursuits of criminals; criminals holding up tourist buses and private cars; intercity or interstate buses and private cars: robbing drivers and passengers. [38]. The study by Barreto et al. [39] reported on criminality with regard to transporting goods in Brazil, where the use of force, violence, and threats to steal goods is most likely to occur on highways or when trucks are parked at key locations on the way to the distribution center.

In this relationship between crime and road safety, Brace et al. [40] suggested that there is a direct correlation between (i) the general negative behavior (e.g., involvement in antisocial behaviors) and risky driving behavior; (ii) criminal behavior and traffic offenses (specifically violence, theft and burglary and recidivist/drink driving, and driving whilst disqualified); (iii) risky traffic behavior contributing to a crash and the criminal record of the perpetrator (particularly for violent crime, vandalism, property crime, and involvement in drug or people trafficking; (iv) involvement in crashes, drink driving, and general criminal record of the perpetrator including theft, car theft, drug and alcohol-related crimes, violence and property damage.

\subsection{The Framework Proposed and the Method FITradeoff.} The purpose of this section is to address the framework applied to the case study and to discuss the method used. Before presenting these, some issues need to be considered.

First, in a multicriteria decision context, a particularly important issue to deal with is the DM's preferential information. In this paper, the DM was judged to have compensatory rationality and the model presented in the next section incorporates a method suitable for this. As to the DM's rationality, it is important to understand the meaning of the preferential information that the model requires. In connection with this, two terms are commonly used in the literature that refers to intercriteria parameters: weights and scales constant. The former represents the relative importance of criteria and is suitable for noncompensatory decisions. The latter is more suitable for compensatory decisions and represents not only the relative importance but incorporates the scale information required for the DM's tradeoffs over the criteria. Nevertheless, in the context of compensatory decisions, the term weights are commonly used for the sake of linguistic simplicity [21]. So, throughout this paper, when the term 'weights' is used, its meaning is that of scale constants.

The other issue, still in relation to the criteria weights, concerns the choice of the FITradeoff method. As discussed in the literature $[26,41-42]$, one of the difficulties in using multicriteria methods to support real-life decisions is the process of eliciting weights. Many methods require the DM to provide the values of the weights directly, which often results in imprecise information, which undermines decision support. Although the methods using the trade-off procedure have contributed to minimizing the difficulty of the process of eliciting weights, much information is still required from the DM. Unlike the traditional trade-off procedure that takes into account the indifference relations, the FITradeoff method admits preference relations, which reduces both the cognitive effort that the DM needs to make and the possibility of inconsistencies regarding the DM's judgment [24]. The procedure for eliciting criteria weights in the FITradeoff method is more flexible does not require direct information and requires less information from the DM. In fact, simulations performed by Mendes et al. [43] show that, in $5 \%$ of the cases, a unique solution can be found after the criteria weights have been ranked using FITradeoff. Also, in $98 \%$ of the cases simulated, the subset of potentially optimal alternatives is reduced after the criteria weights have been ranked.

2.1.1. The Framework. In order to structure the application of FITradeoff in the problem addressed, a framework was developed based on de Almeida et al. [21, 44], based on other real applications of the FITradeoff $[25,45]$. The framework is presented in Figure 1.

The first part of this framework consists of structuring the problem, during which DMs and other actors in the process are identified and objectives, criteria, and decision alternatives are defined. In the problem addressed in this article, the DM represents the Federal Road Police (FRP), and the objective is to identify the most critical sections of a high-traffic road, which is supervised by an FRP unit. The criteria were defined based on the objectives and the sections to be evaluated by these criteria were identified from information obtained from the National Department of Transport Infrastructure (NDTI) and also from qualitative evaluations carried out by the DM.

The objective of the second part is to obtain a ranking of the sections in terms of their criticality and for that purpose the FITradeoff method for ranking was used. Although the method is detailed in the next section, it is emphasized here that, it is applied in two stages. In the first stage, based on the DM's preferences, a ranking of the criteria weights is obtained, and in the second stage, considering the DM's preferences with respect to the performance of some alternatives, a ranking of the road sections is obtained.

Then, the method presents the results and the possibility of carrying out some sensitivity analysis. Discussions were held regarding the results, which was of great value since this helped the DM to understand the tool in greater depth. Further details about this are given in the discussion section. 


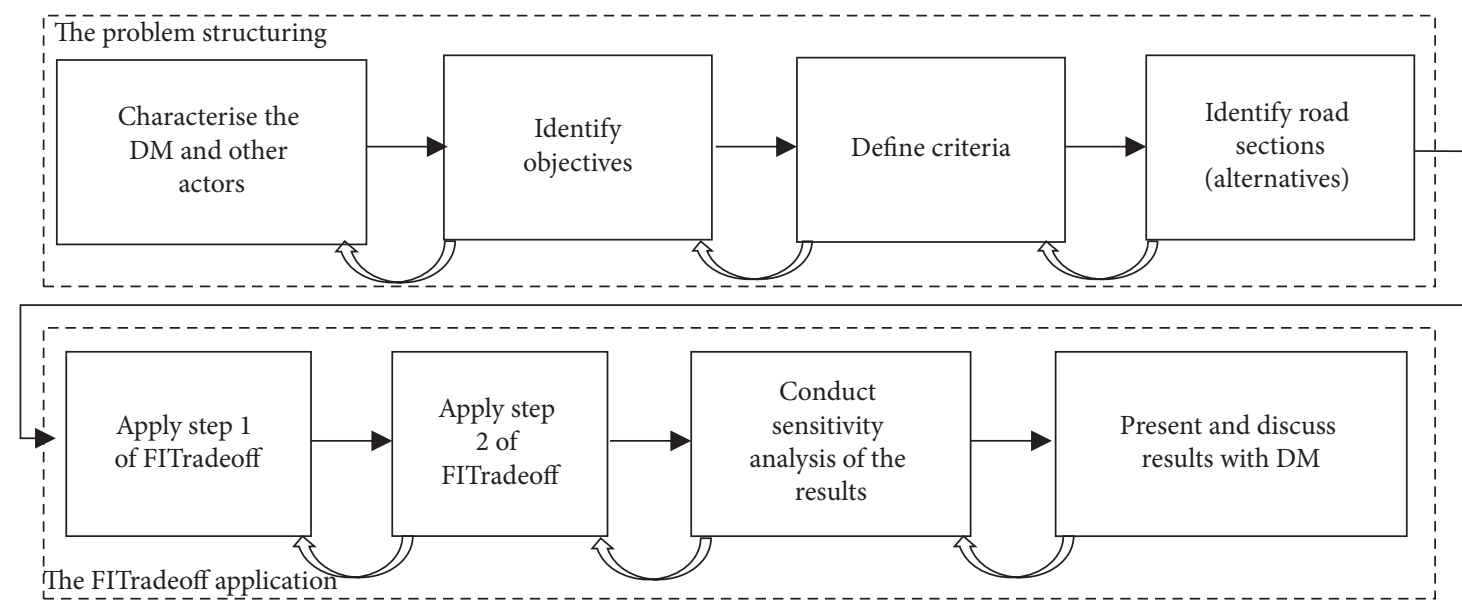

Figure 1: The framework developed for the road section prioritization.

It is important to note that the framework is not a waterfall model. Returning to previous steps is not allowed. In fact, the return to previous steps due to the knowledge, which was built up throughout the process, happened a few times in this application. Also, the framework developed can be replicated in supporting similar problems to the one covered in this paper. Therefore, the criteria and alternatives can be redefined, in addition to which the data used to carry out the assessment of the alternatives can be obtained from other sources.

2.1.2. FITradeoff for Ranking. The decision model that we present in this paper with a view to prioritizing sections of Brazilian roads, according to the criticality related to several aspects associated with the objectives of the institutions responsible for the roads, is based on the method presented by Frej et al. [23].

The decision model calculates the criticality level of each road section $\left(v\left(\mathrm{RS}_{i}\right)\right)$ using the additive model, described in the following equation:

$$
v\left(\mathrm{RS}_{i}\right)=\sum_{j=1}^{m} w_{j} v_{j}\left(\mathrm{RS}_{i j}\right),
$$

where $\mathrm{RS}_{i}$ is a road section $i, \mathrm{RS}_{i j}$ is the finding about the criticality of a road section $i$ in criterion $j$, and $w_{j}$ is the scale constant of criterion $j$ and $v_{j}$ is the intracriterial function of $j$, described in the following equation:

$$
v_{j}\left(\mathrm{RS}_{i j}\right)=\frac{\mathrm{RS}_{i j}-\mathrm{RS}_{j}^{-}}{\mathrm{RS}_{j}^{+}-\mathrm{RS}_{j}^{-}}
$$

where $\mathrm{RS}_{j}^{+}$and $\mathrm{RS}_{j}^{-}$are, respectively, the most critical and the least critical findings among all road sections for criterion $j$.

The FITradeoff method was proposed by de Almeida et al. [24], based on the tradeoff procedure proposed by [46], which has a strong axiomatic structure. The FITradeoff method, however, uses a flexible and interactive procedure that allows the decision model to recommend the best alternative to the DM without needing him/her to provide information at a high cognitive cost. This means that even though the model receives incomplete information, it can provide the DM with a soundly-based recommendation in the context of the objectives set for a choice problematic which does not require all the alternatives to be ranked.

For a ranking problem, however, the FITradeoff adapted by [23] is more appropriate, as it incorporates the concept of pairwise dominance. Thus, it provides information that can be used to obtain a partial or complete ranking, depending on the information provided by the DM in a certain cycle during the implementation of the model, so that he/she can be satisfied with the recommendation provided. In other words, even without a complete ranking, the DM can be satisfied with a partial one that informs him/her of the preferred relationships for the alternatives of his/her greatest interest. The FITradeoff method for the sorting problem can be easily implemented in a decision model using the FITradeoff software which is available at http://fitradeoff.org/.

Initially, the FITradeoff method consists of ranking the criteria according to the value of their scale constants. The criteria ranking step, in the FITradeoff software, can be conducted by two procedures, the holistic evaluation and the pairwise comparison procedure.

In the holistic assessment, the DM is faced with a fictitious consequence, the outcomes of which in each criterion are the least critical $\left(\mathrm{RS}_{j}^{-}\right)$. Then, the DM is asked which criterion, assuming the most critical outcome $\left(\mathrm{RS}_{j}^{+}\right)$, would increase the criticality of the consequence the most. In its first statement, the DM identifies the criterion with the highest scale constant. Then, by asking similar questions, the remaining criteria are ordered so that the order shows which one increases the criticality of the consequence the most after those with a higher impact have been identified, thereby completing the ranking of the criteria.

In the pairwise comparison procedure, two fictitious consequences are presented to the DM so that he/she can identify which is the most critical. Each consequence is represented by the most critical outcome $\left(\mathrm{RS}_{j}^{+}\right)$in one criterion and the least critical $\left(\mathrm{RS}_{j}^{-}\right)$in the other criteria, so that, in the two consequences, the criterion with the most critical outcome is different. According to equations (1) and (2), the value of each consequence is the scale constant value 
of the criterion with the most critical outcome. When the DM chooses the most critical consequence, this means that the value of the scale constant represented by the chosen consequence is greater than the value of the scale constant represented by the other consequence, even though the value of neither is yet known. The rest of the ranking is obtained from the DM's answers to questions about similar pairwise comparisons.

It is important to note that there is an important difference between the two procedures. The holistic evaluation is faster; as the DM only needs to provide $m-1$ statements, while in the ranking procedure by pairwise comparison, this number can be much higher. However, the ranking procedure by holistic evaluation can be cognitively more difficult for the DM, since he/she must consider all the criteria at the same time, especially when he/she defines which is the criterion with the highest scale constant, in the first statement. Thus, the DM can choose the ranking procedure by pairwise comparison if he/she does not feel comfortable about ranking or able to rank the criteria by holistic evaluation.

After ranking the criteria, the model seeks to find a rank among the road sections. The FITradeoff method, Frej et al. [23], solves a linear programming problem for each pair of alternatives $(i, k)$, described by the following equations:

$$
\operatorname{Max}\left(A_{i}, A_{k}\right)=\sum_{j=1}^{m} w_{j} v_{j}\left(A_{i}\right)-\sum_{j=1}^{m} w_{j} v_{j}\left(A_{k}\right), \quad i \neq k
$$

s.t.

$$
\begin{aligned}
& w_{1}>w_{2}>\cdots>w_{m}, \\
& \sum_{j=1}^{m} w_{j}=1, \\
& w_{j} v_{j}\left(x_{j}^{\prime}\right)>w_{j+1}, \quad j=1 \text { to } m-1, \\
& w_{j} v_{j}\left(x_{j}^{\prime \prime}\right)<w_{j+1}, \quad j=1 \text { to } m-1, \\
& w_{j} \geq 0, \quad j=1,2, \ldots, m .
\end{aligned}
$$

Equation (3) calculates the maximum difference in the value between two alternatives $A_{i}$ and $A_{k}$. In our model, the alternatives $A_{i}$ and $A_{k}$ will be road sections. Equation (4) represents the constraints related to the ranking between the scale constants of the criteria. Equation (5) represents the constraint that obliges the scale constants to be normalized. Equations (6) and (7) define the maximum and minimum limits of a scale constant, when compared to a partial value of the scale constant immediately above in the ranking. In our model, initially $x_{j}^{\prime}$ and $x_{j}^{\prime \prime}$ assume the values of $\left(\mathrm{RS}_{j}^{+}\right)$and $\left(\mathrm{RS}_{j}^{-}\right)$, respectively. Equation (8) represents the non-negativity constraint of the scale constants.

According to Frej et al. [23], three situations can occur when comparing two alternatives using the FITradeoff results for ranking. If $\operatorname{Max}\left(A_{i}, A_{k}\right)<0$, then $A_{k}$ dominates $A_{i}$. If $\operatorname{Max}\left(A_{i}, A_{k}\right)<\varepsilon$ and $\operatorname{Max}\left(A_{k}, A_{i}\right)<\varepsilon$, then $A_{i}$ and $A_{k}$ are indifferent, considering the current weight subspace of the problem. If $\operatorname{Max}\left(A_{i}, A_{k}\right)>0$ and $\operatorname{Max}\left(A_{k}, A_{i}\right)>0$, then $A_{i}$ and $A_{k}$ are incomparable considering the current weight subspace of the problem. By using the preference relations obtained from the pairwise comparisons, the model can obtain a partial or complete ranking of alternatives based on the weight subspace obtained with the partial information that the DM has provided.

If the DM is not satisfied with the information obtained with the ranking of the criteria, the FITradeoff method for ranking continues the flexible elicitation procedure. This presents the DM with two consequences in each cycle, similar to the procedure for ranking the criteria by pairwise comparison. However, in this step, in the consequence that represents the criterion with the highest scale constant, an intermediate outcome is presented, between the most and least critical. The DM can choose one of the consequences as being the most critical, or he/she can declare indifference or not answer the question if he/she does not feel able to or prefers not to answer, thus moving on to the next question, if it is still possible to explore the weight subspace.

If the DM chooses one of the consequences or declares indifference, the current subspace of weights is reduced by adjusting the vectors $X_{j}^{\prime}$ and $X_{j}^{\prime \prime}$, and solving again the linear programming problems described in equations (3)-(8). These cycles are repeated. The elicitation procedure ends if the model finds a complete order, if the DM is satisfied with the partial result or if it is not possible to obtain more information from the DM.

\section{Case Study}

The model presented was applied to the problem of prioritizing sections of roads according to the criticality for action planning by the Federal Road Police (FRP) in the state of Pernambuco, Brazil. To do so, several road sections under the jurisdiction of the FRP team were considered, so that by identifying the most critical sections, the planning of actions and investments could be better directed and consequently dealt with in greater detail. As previously noted, it is noteworthy that one of the FRP's functions, besides endeavoring to ensure the safety of road traffic, is to be the police force for the jurisdiction of federal highways, i.e., one duty of the FRP is to prevent and combat crimes and violence that occur on these highways.

For the DM, among the objectives considered in the problem that makes a road section critical are the damage (impacts) to human beings resulting from traffic accidents, issues related to violence/crime, and characteristics/conditions of the road and its traffic. Therefore, several criteria $j$ were chosen, together with the DM, that assess the extent to which these objectives have been achieved: $c_{1}$ : accident rate $\left(I_{n}\right) ; c_{2}$ : index of accidents with fatal victims $\left(I_{F}\right) ; c_{3}$ : index of people with serious injuries involved in traffic accidents $\left(I_{\mathrm{SI}}\right) ; c_{4}$ : index of people with minor injuries involved in traffic accidents $\left(I_{\mathrm{MI}}\right) ; c_{5}$ : index of traffic accidents with damage only to property $\left(I_{\mathrm{DP}}\right), c_{6}$ : percentage of heavy vehicles in road traffic (such as trucks, buses) $\left(\% N_{\mathrm{HV}}\right) ; c_{7}$ : percentage of motorcycles in road traffic $\left(\% N_{\mathrm{MC}}\right) ; c_{8}$ : 
Pavement characteristics/conditions (PAV); $c_{9}$ : Signaling characteristics/conditions (SIN); $c_{10}$ : Characteristics of the track geometry (GEO); $c_{11}$ : criminality (CRIM). The criterion $C_{1}$ is related to the frequency of traffic accidents, $c_{2}$ to $c_{4}$ are related to objective damage to human beings resulting from traffic accidents. Furthermore, criterion $C_{5}$ considers the material losses resulting from a traffic accident. The criteria $c_{6}$ to $c_{10}$ are related to objective characteristics/ conditions of the road and its traffic, and finally, criterion $c_{11}$ is related to the objective issues related to violence (crime).

It is important to highlight here the importance of the decision-maker in a multicriteria decision problem since issues that range from defining the decision criteria to eliciting the parameters of the model are relevant to the DM. In other words, the way that criteria are presented here are appropriate for this case study, but that does not mean that they will be relevant in any other problem. Each multicriteria decision problem needs a structuring stage, represented by the first stage of Figure 1. The model presented has the flexibility to adapt to other decision problems, and this includes being used to elicit parameters for which the FITradeoff method is used. It takes into account, partially or totally, the criteria of this case study, as well as other criteria.

The first seven criteria are continuous and quantitative criteria, in order to measure the criticality of the roads. The DM wishes to maximize them because the DM wants to identify which road section has the worst indices (or highest values) that make them critical. The indices described above are calculated from equation (9) to equation (13) associated with road section $i$.

$$
\begin{gathered}
I_{n}=\frac{10^{6} n_{i}}{365(\mathrm{AADT})_{i} L_{i}}, \\
I_{F}=\frac{10^{6} n_{F_{i}}}{365(\mathrm{AADT})_{i} L_{i}}, \\
I_{\mathrm{SI}}=\frac{10^{6} n_{\mathrm{SI}_{i}}}{365(\mathrm{AADT})_{i} L_{i}}, \\
I_{\mathrm{MI}}=\frac{10^{6} n_{\mathrm{MI}_{i}}}{365(\mathrm{AADT})_{i} L_{i}}, \\
I_{\mathrm{DP}}=\frac{10^{6} n_{\mathrm{MD}_{i}}}{365(\mathrm{AADT})_{i} L_{i}},
\end{gathered}
$$

where $\mathrm{AADT}_{i}$ is the average annual daily traffic; $L_{i}$ is the length of the road section $i$ in kilometers; $n_{i}$ is the annual number of accidents in section $i ; n_{F_{i}}$ is the number of traffic accidents with fatality victims; $n_{\mathrm{SI}_{i}}$ is the number of people with serious injuries involved in traffic accidents related to section $i ; n_{\mathrm{MI}_{i}}$ is the number of people with minor injuries involved in traffic accidents related to section $i ; n_{\mathrm{MD}_{i}}$ is the number of traffic accidents with damage only to property.

Criterion $c_{6}$ reflects issues associated with the risk of heavy vehicles being involved in serious accidents and high secondary accidents. As the demand for freight transportation has increased in recent years, traffic agencies have become more interested in monitoring the risk of heavy vehicles being involved in accidents [47].

Criterion $c_{7}$ reflects exposure to motorcycle accidents since victims of accidents caused by motorcycles and nonmotorized means of transport (bicycles and carts) have higher accident rates with serious injuries on roads when compared to other types of vehicles [48].

Criterion $c_{8}$ (pavement) identifies the characteristics of the road pavement, in which information about the surface condition, speed due to the condition of the pavement, and the presence of critical points are considered and are described on a nominal scale; criterion $c_{9}$ (signage) identifies the presence and conditions of horizontal signage (central and lateral lanes), vertical signage (presence of speed signs, indication signs and intersection, and visibility signs and legibility of all signs, which are described on a nominal scale. In criterion $c_{10}$ (road geometry), the conditions of the geometric characteristics of the road are identified, subdivided into the type of road, road profile, presence of additional lane, presence of bridges and viaducts, presence of dangerous curves, and condition the dangerous curve, which are described on a nominal scale. For further details about the qualitative scales of these criteria see CNT [49].

Finally, criterion $c_{11}$ (criminality) considers the number and the frequency and types of road crimes that fall under the jurisdiction of the FRP. Table 1 presents the qualitative scales of criteria from $c_{8}$ to $c_{11}$.

For the case study, 22 road sections are considered. Table 2 shows these road sections, the average annual daily traffic (AADT) of these sections, the length $(L)$ of the road sections in kilometers, and the performance of these sections for the criteria considered.

On being given this information, initially, the DM was informed about the questions that he would be asked and what options of the answers he could provide. He was also advised that he could return to previous phases if he so desired. The FITradeoff method was applied using software downloaded from http://fitradeoff.org/.

The DM was asked to rank the criteria using the holistic evaluation, which is faster. However, he did not feel able to do so due to the high degree of complexity of the problem, the high number of criteria, and his inexperience of working with multicriteria decision methods.

It is important to note that the FITradeoff software is flexible. Therefore the procedure for ranking the criteria can be changed. For this, it was decided to switch to the pairwise comparison procedure for ranking the criteria, with which the DM felt more comfortable, even though he would have to answer more questions to reach the complete ranking of the criteria when compared to the holistic evaluation. Figure 2 shows one of the steps of ranking the criteria by pairwise comparison.

The FITradeoff method asked the DM thirty questions to rank the criteria. However, the DM had no difficulty in providing the answers, so that despite there being a higher number of questions, the procedure was considered quick and clear. The criteria were ranked as follows: CRIM $>$ $I_{F}>I_{\mathrm{SI}}>I_{\mathrm{MI}}>I_{n}>I_{\mathrm{DP}}>\mathrm{SIN}>\% N_{\mathrm{MC}}>\mathrm{PAV}>\% N_{\mathrm{HV}}>\mathrm{GEO}$. 
TABLE 1: Qualitative scales of the criteria of pavement, signage, road geometry, and criminality.

\begin{tabular}{|c|c|c|c|c|}
\hline Level & Pavement $\left(c_{8}\right)$ & Signage $\left(c_{9}\right)$ & Road geometry $\left(c_{10}\right)$ & Criminality $\left(c_{11}\right)$ \\
\hline 1 & $\begin{array}{l}\text { Very bad } \\
\text { conditions }\end{array}$ & Missing signage in all (or almost all) the section & $\begin{array}{r}\text { Very bad ge } \\
\text { of } \mathrm{t}\end{array}$ & $\begin{array}{r}\text { Very } \\
\mathrm{cr}\end{array}$ \\
\hline 2 & Bad conditions & $\begin{array}{l}\text { Missing signage in parts o } \\
\text { unclear signage in ma }\end{array}$ & $\begin{array}{c}\text { Bad geomet } \\
\text { the }\end{array}$ & \\
\hline 3 & $\begin{aligned} & \mathrm{P}-1 \\
& \mathrm{co}\end{aligned}$ & Damaged or unclear si & $\begin{array}{r}\text { Regular g } \\
\text { of }\end{array}$ & $\begin{array}{r}\text { Mode } \\
\mathrm{cr}\end{array}$ \\
\hline 4 & $\begin{array}{l}\text { Good } \\
\text { conditions }\end{array}$ & $\begin{array}{l}\text { Damaged or unclear signage in some few parts of the } \\
\text { section }\end{array}$ & $\begin{array}{l}\text { Good geome } \\
\text { the }\end{array}$ & $\begin{array}{l}\text { Lov } \\
\text { cri }\end{array}$ \\
\hline 5 & $\begin{array}{l}\text { Very good } \\
\text { conditions }\end{array}$ & Signage in all sections and is very clear & $\begin{array}{l}\text { Very good geometric } \\
\text { characteristics of the road section }\end{array}$ & $\begin{array}{l}\text { Very low level of } \\
\text { criminality }\end{array}$ \\
\hline
\end{tabular}

TABLE 2: Road sections data.

\begin{tabular}{lccccccccccccc}
\hline & AADT & $L(\mathrm{~km})$ & $I_{N}$ & $I_{F}$ & $I_{S I}$ & $I_{\mathrm{MI}}$ & $I_{\mathrm{DP}}$ & $\% N_{\mathrm{HV}}$ & $\% N_{\mathrm{MC}}$ & PAV & SIN & GEO & CRIM \\
\hline A1 & 4808 & 3 & 3.039 & 0.000 & 0.570 & 2.849 & 0.570 & 0.148 & 0.143 & 5 & 3 & 4 \\
$\mathrm{~A} 2$ & 5284 & 3 & 1.383 & 0.000 & 0.346 & 0.519 & 0.519 & 0.128 & 0.146 & 5 & 3 & 4 \\
$\mathrm{~A} 3$ & 4808 & 11 & 1.295 & 0.155 & 0.207 & 0.829 & 0.415 & 0.148 & 0.143 & 2 & 1 & 4 \\
$\mathrm{~A} 4$ & 5284 & 11 & 0.424 & 0.047 & 0.047 & 0.330 & 0.094 & 0.128 & 0.146 & 2 & 1 & 4 \\
$\mathrm{~A} 5$ & 4471 & 9 & 0.817 & 0.068 & 0.272 & 0.477 & 0.136 & 0.178 & 0.138 & 4 & 2 & 4 \\
$\mathrm{~A} 6$ & 4693 & 9 & 0.843 & 0.065 & 0.130 & 0.714 & 0.195 & 0.162 & 0.140 & 4 & 2 & 4 \\
$\mathrm{~A} 7$ & 4134 & 1 & 0.000 & 0.000 & 0.000 & 0.000 & 0.000 & 0.213 & 0.132 & 3 & 4 & 4 \\
A8 & 4102 & 1 & 1.336 & 0.000 & 0.000 & 0.000 & 1.336 & 0.206 & 0.133 & 3 & 2 & 4 \\
A9 & 4134 & 4 & 0.166 & 0.000 & 0.166 & 0.166 & 0.000 & 0.213 & 0.070 & 3 & 3 & 3 \\
A10 & 4102 & 4 & 0.835 & 0.000 & 0.501 & 0.835 & 0.000 & 0.206 & 0.071 & 3 & 3 & 3 \\
A11 & 4134 & 7 & 0.663 & 0.000 & 0.000 & 0.379 & 0.379 & 0.213 & 0.070 & 3 & 3 & 2 \\
A12 & 4102 & 7 & 0.668 & 0.000 & 0.095 & 0.859 & 0.000 & 0.206 & 0.071 & 3 & 3 & 2 \\
A13 & 4744 & 8 & 0.361 & 0.000 & 0.072 & 0.217 & 0.144 & 0.276 & 0.065 & 2 & 3 & 4 \\
A14 & 4770 & 8 & 0.359 & 0.000 & 0.000 & 0.431 & 0.000 & 0.281 & 0.064 & 2 & 3 & 4 \\
A15 & 4723 & 7 & 0.580 & 0.083 & 0.083 & 0.663 & 0.083 & 0.283 & 0.064 & 3 & 1 & 2 \\
A16 & 4785 & 7 & 0.900 & 0.164 & 0.327 & 0.736 & 0.164 & 0.291 & 0.063 & 3 & 1 & 2 \\
A17 & 2738 & 53 & 0.529 & 0.057 & 0.227 & 0.397 & 0.094 & 0.354 & 0.064 & 4 & 2 & 4 \\
A18 & 2743 & 53 & 0.603 & 0.057 & 0.057 & 0.452 & 0.132 & 0.360 & 0.063 & 4 & 2 & 4 \\
A19 & 5211 & 6 & 0.263 & 0.000 & 0.000 & 0.263 & 0.088 & 0.387 & 0.067 & 4 & 2 & 4 \\
A20 & 5177 & 6 & 0.265 & 0.000 & 0.265 & 0.176 & 0.000 & 0.391 & 0.066 & 4 & 2 & 4 \\
A21 & 4147 & 30 & 0.198 & 0.044 & 0.110 & 0.110 & 0.022 & 0.353 & 0.071 & 4 & 2 & 3 \\
A22 & 3908 & 30 & 0.234 & 0.023 & 0.094 & 0.210 & 0.023 & 0.317 & 0.074 & 4 & 2 & 3 \\
\hline
\end{tabular}

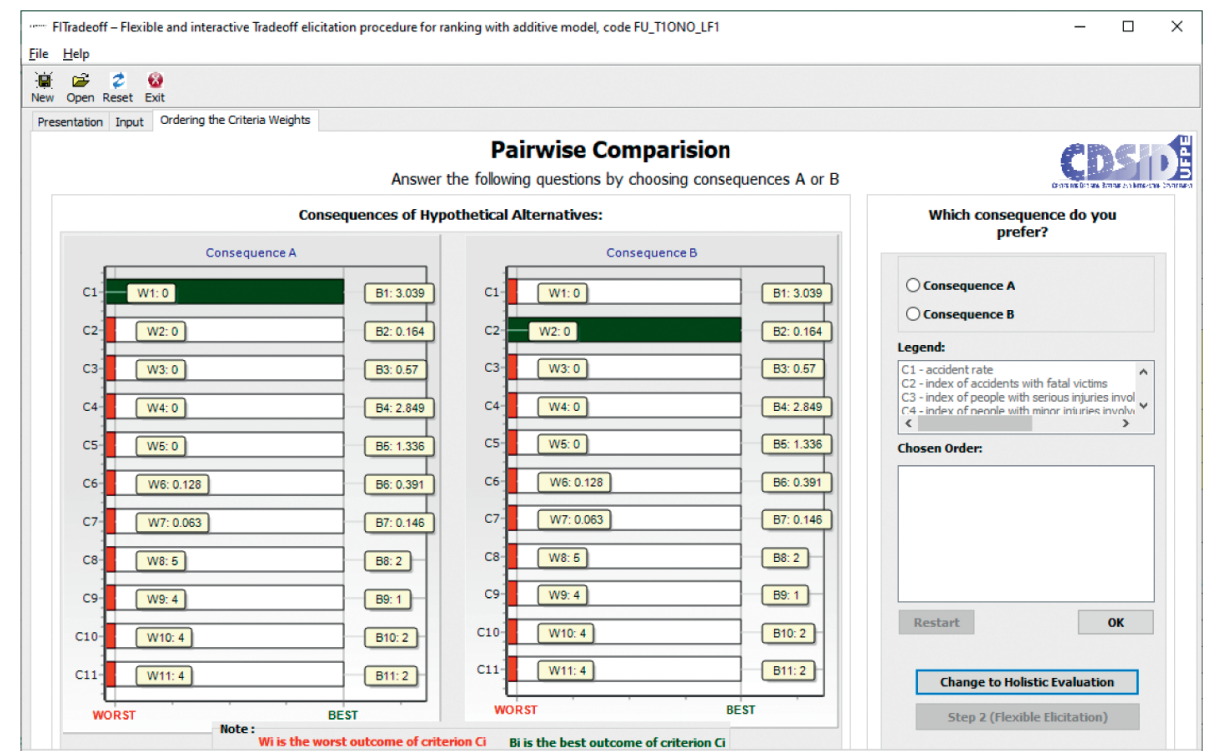

FIgURE 2: Pairwise comparison procedure for ranking the criteria using FITradeoff software. 
After ranking the criteria, the FITradeoff has already provided partial information with only two ranked positions for the alternatives (road sections); it has identified that A9 and A19 were the least critical, occupying the second position, while the other 20 alternatives were in the first position.

The DM considered that this information was insufficient. Thus, the second step of FITradeoff was carried out for which the flexible elicitation procedure was used. In this step, the DM was asked to choose the most critical of two consequences, similar to the first step. In this step, however, the consequence that represented the criterion in a higher position in the criteria ranking presented an intermediate outcome between the least and the most critical. Figure 3 presents FITradeoff's first question for the flexible elicitation procedure, which, by comparing the first ranked criterion with the last, seeks to identify the pattern of the distribution of weights. The subsequent questions compare adjacent criteria in the ranking.

After the DM has provided each answer, the model reduces the weight space according to the information obtained and recalculates the ranking of the road sections according to equations (3)-(8). Table 3 describes the first 13 questions of the flexible elicitation step. The first, second, and third columns show the outcome of the criteria represented by the two consequences presented to DM. The criteria are numbered by their position in the ranking. The fourth column shows the DM's answer, and the last column shows how many levels in the ranking of the road sections have been defined by FITradeoff with the information obtained.

After thirteen questions, the FITradedoff method defined fourteen ranking levels with the information obtained. Although the model did not provide a complete ranking, the DM was satisfied with the result provided after the thirteenth question. Figure 4 shows the last question answered by the DM.

The results identified the ordered ranking of the six most critical road sections, as well as the three least critical. Figure 5 shows the Hasse diagram provided by the FITradeoff software, which presents the preference relations between the alternatives, as well as the ordering levels.

\section{Results and Discussion}

The results presented by the model identified fourteen ranking levels. The first six positions in the ranking were well defined. The DM found the Hasse diagram quite enlightening. According to Figure 5, the road section 16 (A16) is considered the most critical. It can be seen from Table 2 that this road section has the most critical outcomes for the criteria of criminality and the index of accidents with fatalities. These are the criteria with the highest weights according to the information obtained from the DM.

Despite the incomplete ranking, the DM found the clear definition of the first six levels in the ranking very useful, since these show the roads sections that should be prioritized in future FRP actions.

Road sections 03,21 , and 22 occupy level seven in the ranking. Although there is no clear definition of which road section occupies the seventh level, the diagram shows the preference relations that can be identified between the three alternatives. The DM considered that this was very useful. This was because, despite there being preference relations defined for sections 21 and 22, the position itself had not yet been determined because there was not enough information to define the criticality of these road sections, when compared to road section 03, with an incomparable relation, within the information obtained until the thirteenth question of flexible elicitation. This also occurs at level 11, where it is not possible to establish a preference relationship between road sections 02 and 04 .

The greatest lack of information, however, can be identified in position 08 , which are occupied by six road sections $(01,05,11,12,13$, and 14$)$. However, some relations are defined. Many road sections occupy position 08 due to the difficulty of comparing road section 01 with the other ones which is considered incomparable with all other road sections within this level in the ranking. It can also be seen that with the level of information obtained, it was not possible to establish a preferential relation among road sections 05,11 , and 14 .

The DM, however, found the information provided by FITradeoff quite useful, as in a practical decision, the identification of the most critical road sections would be sufficient to prioritize the most important actions and even for lower positions in the ranking, although the information is incomplete, nevertheless, it could guide decisions that are considered less important.

The DM considered it was very useful to have the support of the analyst when using the software which he found easy to understand. He also appreciated the software being flexible. For example, the fact that it is possible to change the procedure for ranking the criteria and to return to previous steps. The use of graphic visualization to support the elicitation process was also considered one of the advantages in the process.

The results obtained from FITradeoff software also provided the possible weight values for each criterion considered in the decision. The limits that define the subspace of weights delimited by the information obtained up to the thirteenth question are shown in Figure 6 and Table 4. These are partial results from the FITradeoff software.

Note that there is a greater concentration of weights in the criteria related to the objectives of combatting crime and the index of accidents with fatal victims. It is important to note that the scale constant does not only consider the relative importance of the decision criterion but also information on the scale of the outcomes of the alternatives in the problem. This means that not only does the relative importance of the criterion affect the value of its scale constant but also the variation in performance between the 


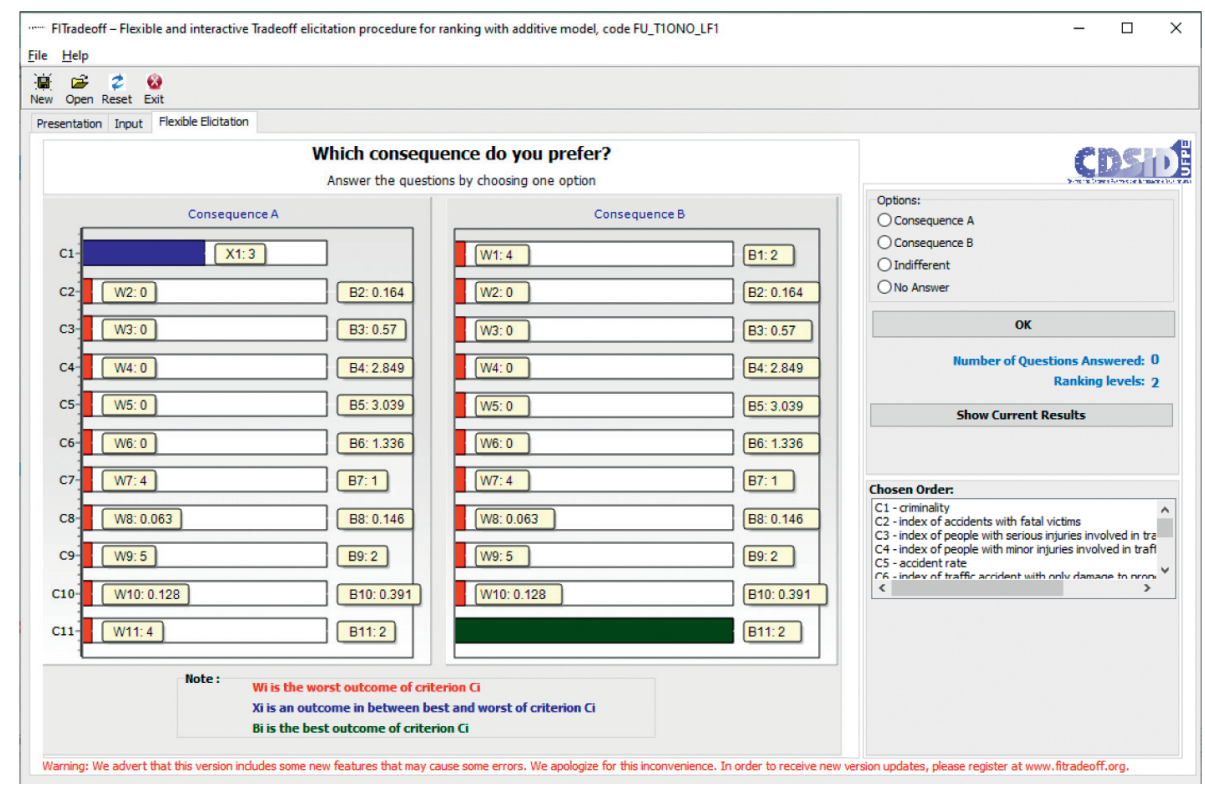

FIgURE 3: The first question for the flexible elicitation procedure using FITradeoff software.

TABle 3: Data on road sections.

\begin{tabular}{lcccc}
\hline Pairwise assessment & Consequence A & Consequence B & DM's answer & Ranking levels \\
\hline 1 & 3 of C1 & 2 of C11 & $\mathrm{A}$ & 2 \\
2 & 3 of C1 & 0.164 of C2 & B & 2 \\
3 & 0.082 of C2 & 0.57 of C3 & Indifferent & 4 \\
4 & 0.0285 of C3 & 2.849 of C4 & A & 4 \\
5 & 1.425 of C4 & 3.039 of C5 & A & 7 \\
6 & 1.52 of C5 & 1.336 of C6 & A & 10 \\
7 & 0.668 of C6 & 1 of C7 & A & 10 \\
8 & 3 of C7 & 0.146 of C8 & B & 10 \\
9 & 0.105 of C8 & 2 of C9 & B & 10 \\
10 & 4 of C9 & 0.391 of C10 & B & 10 \\
11 & 0.26 of C10 & 2 of C11 & B & 10 \\
12 & 2 of C1 & 0.164 of C2 & A & 14 \\
13 & 0.1425 of C3 & 2.849 of C4 & B & 14 \\
14 & 0.712 of C4 & 3.039 of C5 & B & \\
\hline
\end{tabular}

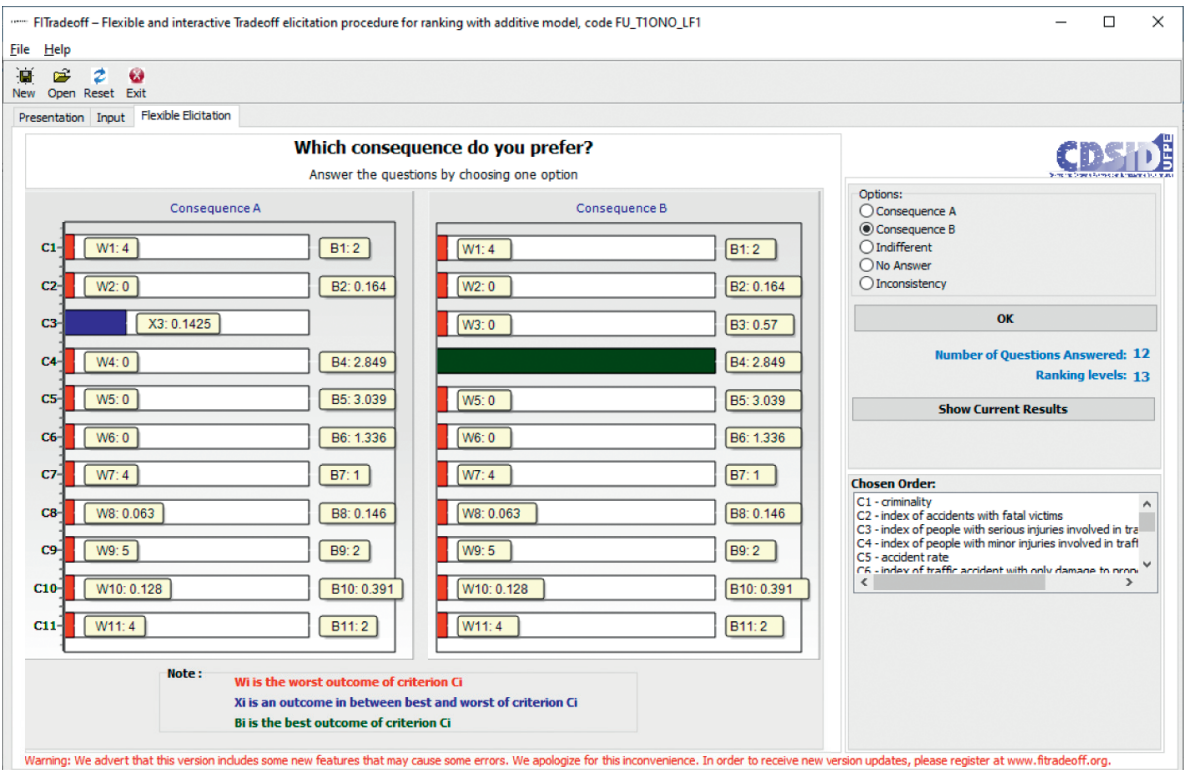

FIGURE 4: The last question for the flexible elicitation procedure using FITradeoff software. 


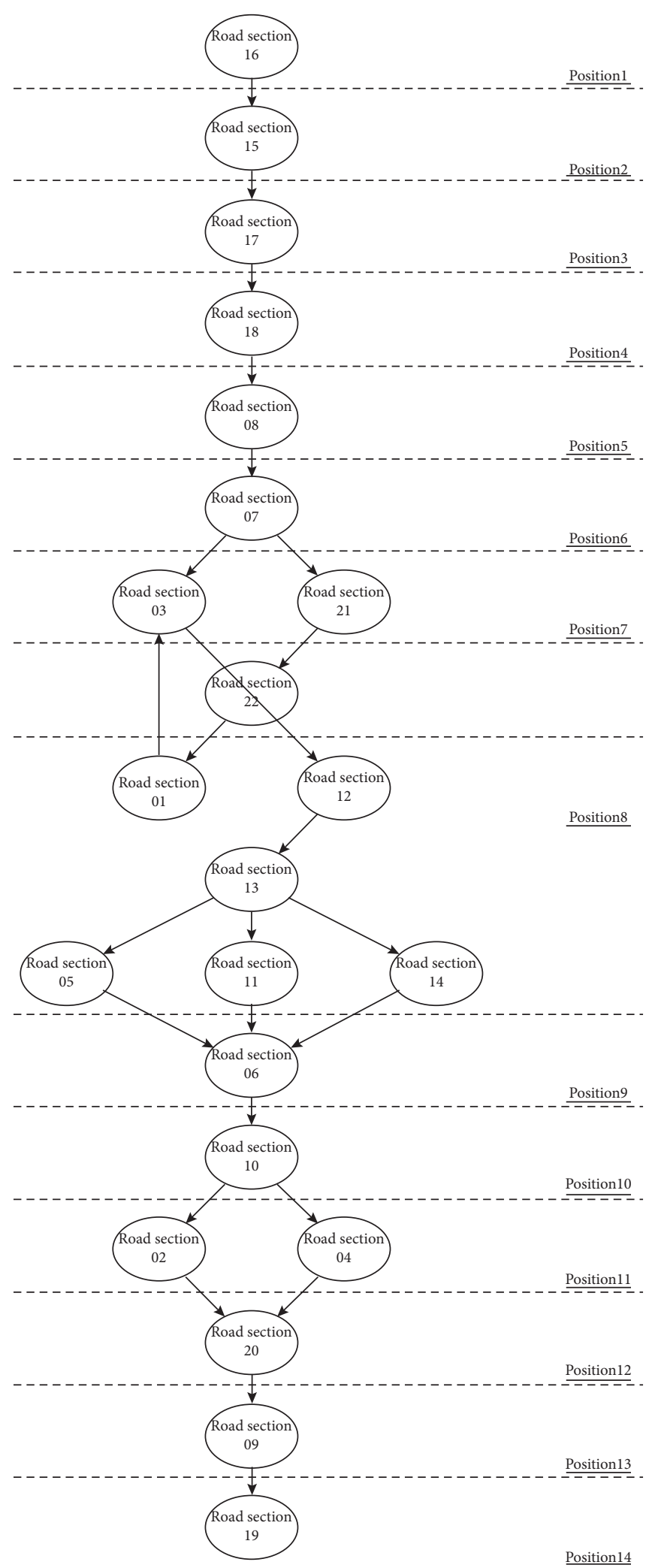

FiguRE 5: Hasse diagram of the preference relations between the alternatives, as well as the ordering levels provided by the FITradeoff software.

alternative with the lowest and the highest outcome. Scale constants of criteria with a greater range can assume a higher value.
The information obtained on the criminality criterion is related to the extent to which the FRP is commonly called for due to the crimes in each section considered in the problem 


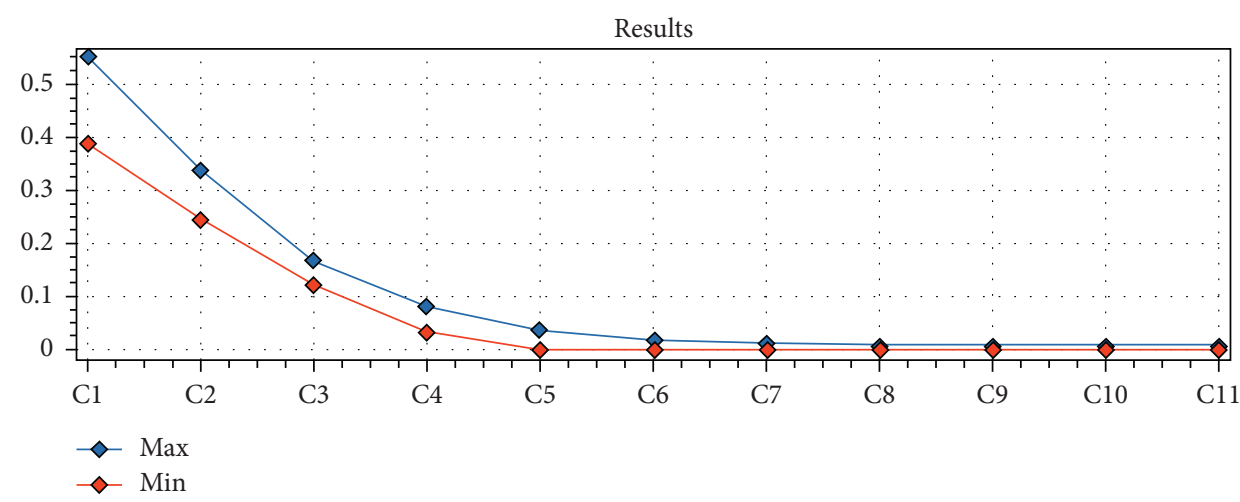

Figure 6: The limits that define the subspace of weights delimited by the information obtained up to the thirteenth question.

TABLE 4: The limits that define the subspace of weights delimited by the information obtained up to the thirteenth question.

\begin{tabular}{|c|c|c|c|c|c|c|c|c|c|c|c|}
\hline & C1 (CRIM) & $\mathrm{C} 2\left(I_{F}\right)$ & C3 $\left(I_{\mathrm{SI}}\right)$ & $\mathrm{C} 4\left(I_{M I}\right)$ & C5 $\left(I_{N}\right)$ & C6 $\left(I_{\mathrm{DP}}\right)$ & C7 (SIN) & $\mathrm{C} 8\left(\% N_{\mathrm{MC}}\right)$ & C9 (PAV) & $\mathrm{C} 10\left(\% N_{\mathrm{HV}}\right)$ & C11 (GEO) \\
\hline Min $k$ & 0.389 & 0.244 & 0.122 & 0.033 & 0.000 & 0.000 & 0.000 & 0.000 & 0.000 & 0.000 & 0.000 \\
\hline $\operatorname{Max} k$ & 0.552 & 0.338 & 0.169 & 0.081 & 0.039 & 0.019 & 0.009 & 0.009 & 0.009 & 0.009 & 0.009 \\
\hline
\end{tabular}

and the extent to which this varies between sections. If all sections have an equally high or equally low level of crime, the variation in crime between sections would not be large and that would make the scale constant have a lower value. The criteria of pavements, signs, geometry, and crime are constructed criteria, which means that it does not make sense to analyze only the difference between classes for each criterion, but what they mean for the DM, which has an impact on the definition of the constant of scale. The meaning of the classes in these criteria for the DM is considered in each step of the FITradeoff method.

Although the criteria related to the characteristics and conditions of the road sections, C7 to C11 in the criteria ranking have very low weights; it can nevertheless be seen that together these criteria can significantly affect the criticality of the decision, considering the information obtained up to the end of the elicitation process. This demonstrates that the objectives represented by these criteria should not be disregarded in the decision.

The possibility of dealing with partial information is another advantage of the model. Despite the problem having eleven criteria, only thirteen questions were necessary before obtaining a satisfactory result for the DM. Compared with models that require complete information about weights and indifference ratios, the DM would have to make at least ten statements of indifference about the adjacent criteria in the ranking. However, it is very difficult for the DM to provide statements of indifference directly.

Considering another scenario that softens the process of obtaining indifference, two approach questions, and a third determination question for each indifference would be asked, totaling $3(n-1)$ statements from DM. In this case, the DM would have to answer thirty questions to define all weights.

When compared to these complete information approaches for obtaining weights, note that, in addition to the model requiring the DM to provide fewer answers, the questions are based mainly on strict preference relations, which are easier to provide, resulting in a faster procedure with fewer inconsistencies.

\section{Conclusions}

Traffic accidents, in addition to being responsible for one of the biggest causes of death worldwide, represent a considerable economic and social cost for countries, especially middle-income countries. In Brazil, this situation is not different. In 2015, it occupied the fourteenth position in the world ranking that considers the ratio between the number of deaths and the total number of inhabitants.

The risk of accidents can be reduced by first identifying the most critical locations and then establishing a policy to improve the level of safety and security on the roads by prioritizing the most critical road sections. In order to define the most critical locations, it was noticed that several factors influence traffic safety and road security, which causes the problem to be characterized as a multicriteria problem.

After an analysis of the characteristics of the problem, in terms of the decision actors, the data available, and the objectives, the applicability of the FITradeoff method for ranking the most critical road sections was presented as a tool to support the decision.

Hence, a case study was carried out on 22 road sections and 11 evaluation criteria. The variety of criteria considered by the DM well represents the diversity and multiplicity of factors that affect the issue of road safety. The criteria considered included aspects associated with damage (impacts) to humans, issues related to violence, and characteristics/conditions of the road and its traffic.

FITradeoff was applied considering the DM's preferences which were obtained by analysing his answers to the system's questions. The entire process was supported by the software. As presented, after ordering the criteria weights, 2 levels of the ranking were defined and after 13 interactions with the 
DM, 14 levels of ranking, and the 6 most critical sections were identified.

The criticality of road sections was represented through a diagram that presents the rank according to the DM objectives. The definition of the six most critical road sections in a precise rank position is provided.

The criticality of the road sections was represented by means of a diagram that presents the ranking according to the DM's objectives. The definition of the six most critical road sections in an accurate ranking position provided the DM with information that allows for proper planning of future actions. Other road sections have an intermediate position in the less defined rank, but still, provide the DM with partial information that can contribute to the planning of actions in sections considered less critical.

Given this result, the DM felt more confident in directing the available resources (such as financial resources, work team, vehicles, radar, and extrasignage) to prevent and mitigate traffic accidents for the prioritized sections. This reflects the confidence that the DM has in the statements he provided since the model requires less information, and such information is obtained by asking the DM questions that he found easier to answer.

Future studies could usefully investigate improving the decision model by examining the DM's evaluation as to the effectiveness and efficiency of using the resources available on the different road sections prioritized. Normally, each preventive/mitigating action directs "energy" towards diminishing or eliminating some dimensions of consequences, e.g., an action of the patrol system regarding the use of police vehicles can reduce the level of violence (criminality). However, this may have little impact on the issues associated with the road pavement, with a view to improving road safety.

\section{Data Availability}

All data are available within the paper.

\section{Conflicts of Interest}

The authors declare that they have no conflicts of interest.

\section{Acknowledgments}

The authors also thank the National Council for the Improvement of Higher Education (CAPES) and the experts that collaborated with the development of this study. This work was partially supported by the Fundação de Amparo à Ciência e Tecnologia de Pernambuco (FACEPE) (Grant numbers: BPG-0598-3.08-17 and APQ-0370-3.08/14) and Brazilian National Research Council (CNPq) (Grant numbers: 407541/2018-7 and 435680/2018-8).

\section{References}

[1] WHO, Global Status Report on Road Safety 2018, World Health Organization (CC BY- NC-SA 3.0 IGO), Geneva, Switzerland, 2018.
[2] WHO, Road Traffic Injuries, World Health Organization, Geneva, Switzerland, 2018.

[3] WHO, The Top 10 Causes of Death, World Health Organization, Geneva, Switzerland, 2017.

[4] IPEA, Acidentes de Trânsito Nas Rodovias Federais Brasileiras, Instituto de Pesquisa Econômica Aplicada, Brasília, Brazil, 2015.

[5] S. A. R. Shah and N. Ahmad, "Road infrastructure analysis with reference to traffic stream characteristics and accidents: an application of benchmarking based safety analysis and sustainable decision-making," Applied Sciences, vol. 9, no. 11, p. 2320, 2019.

[6] G. Fancello, M. Carta, and P. Fadda, "Road intersections ranking for road safety improvement: comparative analysis of multi-criteria decision making methods," Transport Policy, vol. 80, pp. 188-196, 2019.

[7] (Fórum Brasileiro de Segurança Pública), Anuário Brasileiro de Segurança Pública 2020 [Brazilian Year Book of Public Security 2020], Fórum Brasileiro de Segurança Pública, São Paulo, Brazil, 2020, https://Forumseguranca.Org.Br/WpContent/Uploads/2020/10/Anuario-14-2020-v1-Interativo. Pdf, 14th edition.

[8] M. Justus, V. Ceccato, G. C. Moreira, and T. Kahn, "Crime against trading: the case of cargo theft in São Paulo," Retail Crime, Springer International Publishing, Cham, Switzerland, pp. 297-323, 2018.

[9] B. R. Owabumoye and O. A. Ajala, "The effect of bad road on crime reportage in Southwestern Nigeria: Akure," International Journal of Society Systems Science, vol. 10, no. 2, p. 159, 2018.

[10] Y. Chen, Y. Li, M. King, Q. Shi, C. Wang, and P. Li, "Identification methods of key contributing factors in crashes with high numbers of fatalities and injuries in China," Traffic Injury Prevention, vol. 17, no. 8, pp. 878-883, 2016.

[11] H. Pérez-Acebo, H. Gonzalo-Orden, D. J. Findley, and E. Rojí, "A skid resistance prediction model for an entire road network," Construction and Building Materials, vol. 262, Article ID 120041, 2020.

[12] R. Ziolkowski, "Investigations of driver's speed at unsignalised pedestrian crossings," MATEC Web of Conferences, vol. 262, no. 1, Article ID 05018, 2019.

[13] B. Hofko, H. Kugler, G. Chankov, and R. Spielhofer, "A laboratory procedure for predicting skid and polishing resistance of road surfaces," International Journal of Pavement Engineering, vol. 20, no. 4, pp. 439-447, 2019.

[14] H. Pérez-Acebo, R. Ziółkowski, A. Linares-Unamunzaga, and H. Gonzalo-Orden, "A series of vertical deflections, a promising traffic calming measure: analysis and recommendations for spacing," Applied Sciences, vol. 10, no. 10, Article ID 3368, 2020.

[15] D. Llopis-Castelló and D. J. Findley, "Influence of calibration factors on crash prediction on rural two-lane two-way roadway segments," Journal of Transportation Engineering Part A: Systems, vol. 145, Article ID 04019024, 2019.

[16] Q. Bao, D. Ruan, Y. Shen, E. Hermans, and D. Janssens, "Improved hierarchical fuzzy TOPSIS for road safety performance evaluation," Knowledge-Based Systems, vol. 32, pp. 84-90, 2012.

[17] A. T. de Almeida, M. H. Alencar, T. V. Garcez, and R. J. P. Ferreira, "A systematic literature review of multicriteria and multi-objective models applied in risk management," IMA Journal of Management Mathematics, vol. 28, no. 2, pp. 153-184, Article ID dpw021, 2016. 
[18] T. V. Garcez and A. T. de Almeida, "Multidimensional risk assessment of manhole events as a decision tool for ranking the vaults of an underground electricity distribution system," IEEE Transactions on Power Delivery, vol. 29, no. 2, pp. 624-632, 2014.

[19] M. Tešić, E. Hermans, K. Lipovac, and D. Pešić, "Identifying the most significant indicators of the total road safety performance index," Accident Analysis \& Prevention, vol. 113, pp. 263-278, 2018.

[20] G. Fancello, M. Carta, and P. Fadda, "A decision support system for road safety analysis," Transportation Research Procedia, vol. 5, pp. 201-210, 2015.

[21] A. T. de Almeida, C. A. V. Cavalcante, M. H. Alencar, R. J. P. Ferreira, A. T. de Almeida-Filho, and T. V. Garcez, "Multicriteria and multiobjective models for risk, reliability and maintenance decision analysis," International Series in Operations Research and Management Science, Springer International Publishing, vol. 231Cham, Switzerland, , 2015.

[22] E. A. Frej, L. Reis, P. Roselli, J. A. de Almeida, and A. T. de Almeida, "A multicriteria decision model for supplier selection in a food industry based on FITradeoff method," Mathematical Problems in Engineering, vol. 2017, Article ID 4541914, 9 pages, 2017.

[23] E. A. Frej, A. T. de Almeida, and A. P. C. S. Costa, "Using data visualization for ranking alternatives with partial information and interactive tradeoff elicitation," Operational Research, vol. 19, no. 4, pp. 909-931, 2019.

[24] A. T. de Almeida, J. A. de Almeida, A. P. C. S. Costa, and A. T. de Almeida-Filho, "A new method for elicitation of criteria weights in additive models: flexible and interactive tradeoff," European Journal of Operational Research, vol. 250, no. 1, pp. 179-191, 2016.

[25] A. P. Henriques de Gusmão and C. Pereira Medeiros, "A model for selecting a strategic information system using the FITradeoff," Mathematical Problems in Engineering, vol. 2016, Article ID 7850960, 7 pages, 2016.

[26] M. Riabacke, M. Danielson, and L. Ekenberg, "State-of-the-art prescriptive criteria weight elicitation," Advances in Decision Sciences, vol. 2012, Article ID 276584, 24 pages, 2012.

[27] W. Temrungsie, W. Raksuntron, N. Namee, S. Chayanan, and B. Witchayangkoon, "AHP-based prioritization on road accidents factors: a case study of Thailand," International Transaction Journal of Engineering, Management, \& Applied Sciences \& Technologies, vol. 6, pp. 135-144, 2015.

[28] M. Dell'Ovo, E. A. Frej, A. Oppio, S. Capolongo, D. C. Morais, and A. T. de Almeida, "Multicriteria decision making for healthcare facilities location with visualization based on FITradeoff method," in Proceedings of the Third International Conference on Data, Information and Knowledge Visualization in Decision Support Systems, ICDSST 2017, I. Linden, S. Liu, and C. Colot, Eds., vol. 282, pp. 32-44, , Springer International Publishing, Namur, Belgium, May 2017, Decision Support Systems VII.

[29] G. Fancello, M. Carta, and P. Fadda, "A decision support system based on electre III for safety analysis in a suburban road network," Transportation Research Procedia, vol. 3, pp. 175-184, 2014.

[30] S. Kanuganti, R. Agarwala, B. Dutta, P. N. Bhanegaonkar, A. P. Singh, and A. K. Sarkar, "Road safety analysis using multi criteria approach: a case study in India," Transportation Research Procedia, vol. 25, pp. 4649-4661, 2017.

[31] G. Khorasani, F. Mirmohammadi, H. Motamed, M. Fereidoon, and A. Tatari, "Application of multi criteria decision making tools in road safety performance indicators and determine appropriate method with average concept," International Journal of Innovative Technology and Exploring Engineering, vol. 3, pp. 173-177, 2013.

[32] M. Castro-Nuño and M. T. Arévalo-Quijada, "Assessing urban road safety through multidimensional indexes: application of multicriteria decision making analysis to rank the Spanish provinces," Transport Policy, vol. 68, pp. 118-129, 2018.

[33] M. Rosić, D. Pešić, D. Kukić, B. Antić, and M. Božović, "Method for selection of optimal road safety composite index with examples from DEA and TOPSIS method," Accident; Analysis and Prevention, vol. 98, pp. 277-286, 2017.

[34] F. Chen, J. Wang, and Y. Deng, "Road safety risk evaluation by means of improved entropy TOPSIS-RSR," Safety Science, vol. 79, pp. 39-54, 2015.

[35] E. Hermans, D. Ruan, T. Brijs, G. Wets, and K. Vanhoof, "Road safety risk evaluation by means of ordered weighted averaging operators and expert knowledge," Knowledge-Based Systems, vol. 23, no. 1, pp. 48-52, 2010.

[36] D. S. Rodrigues, P. J. G. Ribeiro, and I. C. da Silva Nogueira, "Safety classification using GIS in decision-making process to define priority road interventions," Journal of Transport Geography, vol. 43, pp. 101-110, 2015.

[37] Y. Shen, E. Hermans, D. Ruan, G. Wets, T. Brijs, and K. Vanhoof, “A generalized multiple layer data envelopment analysis model for hierarchical structure assessment: a case study in road safety performance evaluation," Expert Systems with Applications, vol. 38, no. 12, pp. 15262-15272, 2011.

[38] F. M. Ajide, "Criminal activities and road accidents in Nigerian transport industry," Transportation in Developing Economies, vol. 6, no. 1, p. 6, 2020.

[39] L. P. Barreto, A. S. Silva, and R. C. Ferreira, "Risk analysis of transporting goods by road in Brazil," Supply Chain Design and Management for Emerging Markets, Emerald Publishing Limited, Bingley, UK, pp. 157-174, 2020.

[40] C. Brace, M. Scully, B. Clark, and J. Oxley, "The relationship between crime and road safety," Report No. 284, Monash University Accident Research Centre, Victoria, Australia, 2010.

[41] M. Danielson, L. Ekenberg, A. Larsson, and M. Riabacke, "Weighting under ambiguous preferences and imprecise differences in a cardinal rank ordering process," International Journal of Computational Intelligence Systems, vol. 7, no. 1, pp. 105-112, 2014.

[42] M. Danielson and L. Ekenberg, "An improvement to swing techniques for elicitation in MCDM methods," KnowledgeBased Systems, vol. 168, pp. 70-79, 2019.

[43] J. A. J. Mendes, E. A. Frej, A. T. de Almeida, and J. A. de Almeida, "Evaluation of flexible and interactive tradeoff method based on numerical simulation experiments," Pesqui Operacional, vol. 40, no. 11, 2020.

[44] A. T. de Almeida, D. C. Morais, A. P. C. S. Costa, L. H. Alencar, and S. de F. D. Daher, Decisão em Grupo e Negociação. Métodos e Aplicações, Editora Interciência, Rio De Janeiro, Brazil, 2nd edition, 2019.

[45] T. Poleto, T. R. N. Clemente, A. P. H. de Gusmão, M. M. Silva, and A. P. C. S. Costa, "Integrating value-focused thinking and FITradeoff to support information technology outsourcing decisions," Management Decision, vol. 58, pp. 2279-2304, 2020.

[46] R. L. Keeney and H. Raiffa, Decisions with Multiple Objectives-Preferences and Value Tradeoffs, Cambridge University Press, Cambridge, UK, 1993. 
[47] Y. Jo, C. Oh, and S. Kim, "Estimation of heavy vehicle-involved rear-end crash potential using WIM data," Accident Analysis \& Prevention, vol. 128, pp. 103-113, 2019.

[48] R. P. de Oliveira and J. A. Achcar, "Victims of road accidents with serious injuries and dependence on some individual, climatic and infrastructure factors on federal highways in Brazil," International Journal of Injury Control and Safety Promotion, vol. 27, no. 3, pp. 355-361, 2020.

[49] CNT, Pesquisa CNT de Rodovias 2018 2018:211-5, Confederação Nacional dos Transportes, Brasilia, Brazil, 2020, https://pesquisarodovias.cnt.org.br/Downloads/Edicoes// 2018/Relatório\%20Gerencial/Pesquisa\%20CNT\%20(2018)\% 20-\%20ALTA.pdf. 